\title{
A NEGAÇÃO NO PORTUGUÊS FALADO DO RIO DE JANEIRO: UM ESTUDO BASEADO EM CORPUS
}

\author{
THE SPOKEN PORTUGUESE NEGATION FROM RIO DE JANEIRO: A STUDY BASED \\ ON CORPUS
}

Elizene Sebastiana de Oliveira Nunes

Centro Universitário de Patos de Minas

\begin{abstract}
RESUMO: A negação é um fenômeno comum a várias línguas, podendo se manifestar de formas distintas de uma língua para outra. No português brasileiro, coexistem três estratégias de negação sentencial, quais sejam: a negação pré-verbal (não + SV), a dupla negação (não + SV + não) e a negação pós-verbal (SV + não). Partindo dessa constatação, o presente estudo teve por escopo a análise da variação linguística na estrutura de negação utilizada por falantes do Rio de Janeiro. Essa análise é amparada pela sociolinguística laboviana, demonstrando que a variação presente na língua interrelaciona-se com aspectos sociais, estruturais e funcionais. Utilizou-se, neste trabalho, como corpus, o vernáculo carioca, constituído por 8 amostras que integram a Amostra Censo 1980, organizada por um grupo de pesquisadores do Programa de Estudos sobre o Uso da Língua (PEUL). O presente estudo, por meio de uma análise quali-quantitativa, mostra como fatores externos e internos à estrutura linguística interferem na fala dos cariocas.
\end{abstract}

PALAVRAS-CHAVE: Negação sentencial; Português brasileiro falado; Sociolinguística.

ABSTRACT: Negation is a common phenomenon in many language that can have different ways to happen from language to language. There are three coexistent strategies used to negate in Brazilian Portuguese: the pre-verbal negation (no + SV), the double negation (no + SV + no) and the post-verbal negation (SV + no). Taking this verification into consideration, the present study aimed at analyzing the linguistic variation in the negation structure used by speakers from Rio de Janeiro. This analysis is done based on Labovian Sociolinguistics that demonstrates that language variation is related to social, structural and functional aspects. The corpus used to develop this research was the carioca vernacular consisted of 8 samples that integrate the 1980 Census Sample organized by a group of researchers from the Studies Program about the Usage of Language (PEUL - in Portuguese). By means of a quali-quantitative analysis, this study shows how external and internal factors to the linguistic structure influence on the carioca speech (speech from Rio de Janeiro).

KEYWORDS: Negation; Spoken Brazilian Portuguese; Sociolinguistics.

\section{Considerações iniciais}

Numa concepção funcionalista, não mais se admite o estudo da língua como uma unidade abstrata, isenta também de influências sociais. Dessa forma, assim como a 


\section{Revista do SELL}

v. $4, n^{\circ} .1$

ISSN: $1983-3873$

sociedade apresenta suas diversidades, a língua também as apresentará, sob seus variados aspectos, sejam lexicais, morfológicos ou sintáticos.

Diante disso, os trabalhos que se dedicam à variação e mudança linguística tendem a ganhar espaço e buscam, conforme já apontava Labov ([1972], 2008), estudar os padrões de comportamento linguístico observáveis dentro de uma comunidade de fala e os formaliza analiticamente através de um sistema heterogêneo, constituído por unidades e regras variáveis. Dessa forma, tem-se que, nas comunidades de fala, frequentemente, existirão formas linguísticas em variação, isto é, formas que estão em coocorrência e em concorrência.

Um aspecto linguístico bastante estudado nesta perspectiva tem sido a negação, que é um fenômeno comum a várias línguas, podendo se manifestar de formas distintas de uma língua para outra e ainda de formas variáveis numa mesma língua. Sua realização pode ser expressa por meio de recursos morfológicos, sintáticos e lexicais. De maneira generalizada, a negação linguística é vista como o elemento que, inserido em uma sentença qualquer, causa uma inversão de seu valor de verdade. Assim, pode-se considerar que para toda negativa há sempre uma contrapartida afirmativa.

Feita essa breve contextualização do fenômeno aqui estudado, cabe destacar que o objetivo central deste trabalho foi analisar, sob uma perspectiva funcionalista da linguagem, com aporte teórico na Teoria da Variação e Mudança Linguística Laboviana, a variável dependente "negação sentencial no português falado do Rio de Janeiro", a qual, diferentemente da maioria, que é caracterizada por sua binariedade, é eneária, constituída por três variantes: a negação pré-verbal, a negação dupla e a negação pósverbal. Também foi objetivo do estudo verificar como fatores estruturais e sociais interferem no uso das estratégias de negação no corpus estudado.

Partindo do objetivo central deste estudo, hipotetiza-se que a negação sentencial no Rio de Janeiro esteja passando por um processo de mudança. Entretanto, não podem ser feitas muitas afirmações categóricas, o que só será possível daqui a alguns séculos, talvez, pois é sabido que o processo de mudança é lento e gradual.

\section{Linguagem e sociedade}

Os estudos linguísticos perpassaram diferentes etapas para chegar até o ponto em que se encontram hoje. Antes, a língua era estudada de forma bastante abstrata, uma vez que partia de princípios muito metódicos e não permitia influências do meio social. 


\section{Revista do SELL \\ v. $4, n^{\circ} .1$ \\ ISSN: $1983-3873$}

Era um sistema muito rígido e fechado, o que não correspondia à realidade da linguagem. Com o evoluir dos tempos e das pesquisas linguísticas, a concepção de língua foi incorporando novas definições e, com o surgimento da sociolinguística, percebeu-se que a língua não poderia ser encarada como um processo isento de influências dos sujeitos falantes.

Nota-se, então, que linguagem e sociedade estão ligadas entre si de modo indissociável. A história da humanidade é a história de seres organizados em sociedade e detentores de um sistema de comunicação oral, ou seja, de uma língua. Dentro dessa perspectiva, a língua é concebida como um instrumento de comunicação social, simultaneamente servindo para representar informação, estabelecer identificação de um grupo e acomodar situações sociais. (cf. LABOV, 1982, p. 84)

Nessa perspectiva, é possível perceber que, quando há um comprometimento com uma concepção de linguagem que tem como foco de análise a língua em uso efetivo, compreende-se com facilidade que o sistema de qualquer língua natural, além de heterogêneo, não é estático e, consequentemente, está submetido a pressões de seus usuários, o que acarreta mudanças linguísticas de natureza variada. (cf. GONÇALVES, LIMA HERNANDES e CASSEB GALVÃO, 2007, contracapa).

Com a mudança de foco no estudo da língua, ou seja, com o olhar voltado para a situação de comunicação e as interferências do sujeito falante, abre-se espaço para os estudos das variedades linguísticas e dos processos de mudança da língua. A partir de então, os estudos sociolinguísticos ganham destaque dentro das pesquisas linguísticas.

\subsection{Sociolinguística: breve abordagem de algumas terminologias}

Uma definição sintética do que seja a sociolinguística pode assim ser dada: "é a área que estuda a língua em seu uso real, levando em consideração as relações entre a estrutura linguística e os aspectos sociais e culturais da produção linguística". (cf. CEZARIO e VOTRE, 2011, p. 140).

A sociolinguística tem como cerne o princípio de que a variação e a mudança são inerentes às línguas, não podendo, portanto, serem deixadas de lado na análise linguística. Para os estudiosos dessa área, são as manifestações verbais ocorridas nas diferentes variedades de uma língua seu objeto de estudo. Interessa a eles entender quais são os fatores que motivam a variação linguística e qual a importância de cada um na configuração do quadro que se apresenta variável, permitindo, ao final de um estudo, 


\section{Revista do SELL}

v. $4, n^{\circ} .1$

ISSN: $1983-3873$

avaliar o grau de estabilidade de um fenômeno, se está em seu início/meio (mudança em curso) ou se completou uma trajetória que indica uma mudança findada (cf. CEZARIO e VOTRE, 2011).

Considerando a heterogeneidade dos fenômenos linguísticos, William Labov, precursor dos estudos variacionistas, juntamente com Weinreich e Herzog, propôs um modelo de análise linguística que considera a influência dos fatores sociais atuantes na língua e que ficou conhecido como Teoria da Variação e Mudança Linguística.

A Teoria da Variação e Mudança Linguística (também chamada Sociolinguística Quantitativa ou Laboviana) tem como objeto de estudo a variação e mudança da língua no contexto social da comunidade de fala - que é definida "pela participação num conjunto de normas compartilhadas" (cf. LABOV [1972], 2008, p. 150). Nessa perspectiva, a língua é vista pelos sociolinguistas como dotada de "heterogeneidade ordenada", fator importante na identificação de grupos e na demarcação de diferenças sociais na comunidade. Dessa forma, o domínio de estruturas heterogêneas é parte da competência linguística dos indivíduos.

Assim, o principal meio de investigação em Sociolinguística é o vernáculo, que, para Labov ([1972], 2008, p. 244), é a língua falada em situações naturais de interação social, ou seja, é um "estilo em que se presta o mínimo de atenção ao monitoramento da fala".

A variação linguística seria, pois, nessa concepção, "diversas maneiras alternativas de dizer 'a mesma' coisa” (cf. LABOV, [1972], 2008, p. 221).

Essas formas alternantes de se dizer "a mesma coisa", que formam o caráter heterogêneo da comunidade, são igualmente representacionais, equivalentes no sentido de significado e foram denominadas por Labov ([1972], 2008, p. 25) de variantes linguísticas. Muitas dessas variantes são agrupadas de forma a estigmatizar determinadas ocorrências. Há que ressaltar as variantes livres e combinatórias, as variantes de prestígio, as variantes estigmatizadas, as variantes inovadoras e as conservadoras, dentre outras. Ainda para uma ampla compreensão dessas variantes, devem-se levar em consideração variáveis independentes linguísticas e extralinguísticas. A variável linguística é vista por Labov ([1968], 2006, p. 105) como um "elemento variável dentro do sistema controlado por uma única regra".

As variações correntes na língua podem se esvair com o passar do tempo ou podem, ainda, atingir o nível de mudança linguística, passando a integrar oficialmente uma determinada língua. 


\section{Revista do SELL}

v. $4, n^{\circ} .1$

ISSN: $1983-3873$

2.2 Os cinco problemas labovianos da mudança linguística

Em estudo clássico de 1968, Weinreich, Labov e Herzog já apontavam os problemas que devem ser levados em conta na análise dos fenômenos de mudança linguística. Esses cinco problemas revelam o caminho seguido por uma determinada mudança e são novamente abordados na obra de Labov (1982), assim definidos: fatores condicionantes (constraints problem), transição (transition problem), encaixamento (embedding problem), avaliação (evaluation problem) e implementação (actuation problem). (cf. LABOV, 1982, p. 26-29).

Os fatores condicionantes estão relacionados aos princípios gerais que determinam a mudança, ou seja, neste ponto, há que se saber: "quais são os fatores condicionantes gerais da mudança, se os há, que determinam mudanças possíveis e impossíveis e direções da mudança?"(cf. LABOV, 1982, p. 26, tradução minha').

O problema da transição diz respeito ao caminho da mudança, ou, nas palavras de Labov (1982, p. 27, tradução minha²): "como (por que rota) uma língua muda" ou ainda: "como a língua muda sem interferir na comunicação entre membros da comunidade de fala?" (Ibidem, p. 28). Assim, por exemplo, correlacionando a estrutura linguística variável com fatores da estrutura social, poder-se-ia observar como uma determinada variante estaria se difundindo entre os diversos segmentos sociais.

O problema do encaixamento diz respeito aos fatores internos (linguísticos) e externos (extralinguísticos - sociais) que interferem na mudança linguística. A pergunta chave dessa dimensão, conforme Labov (1982, p. 28, tradução minha ${ }^{3}$ ), é: "Como uma dada mudança linguitica é encaixada no sistema em torno das relações linguísticas e sociais?"

O problema da avaliação diz respeito à forma "como os membros da comunidade de fala avaliam uma dada mudança, e qual é o efeito desta avaliação sobre a

\footnotetext{
${ }^{1}$ What are the general constraints on change, if any, that determine possible and impossible changes and directions of change?

${ }^{2}$ How (by what route) does language change... How can language change from one state to another without interfering with communication among members of the speech community?

${ }^{3}$ How is a given language change embedded in the surrounding system of linguistic and social relations?
} 


\section{Revista do SELL}

v. $4, n^{\circ} .1$

ISSN: $1983-3873$

mudança" (cf. LABOV, 1982, p. 28, tradução minha ${ }^{4}$ ). O autor (ibidem) continua sua explanação afirmando que “a noção de 'avaliação' deve ser tomada aqui para se referir às respostas em todos os níveis de consciência, de discussão aberta a reações que são completamente inacessíveis à introspecção". Labov reconhece ainda um segundo aspecto do problema da avaliação, teorica e metodologicamente bastante distinto: a avaliação linguística da mudança. Este é, segundo ele, equivalente ao principal problema da mudança linguística: "como o sistema muda sem danos à sua função representativa?"(ibidem, p. 29, tradução minha ${ }^{5}$ ).

Por fim, quanto ao problema da implementação, há que se pensar onde e quando as variantes estudadas se espalham ou, nas palavras de Labov (1982, p. 29, tradução minha ${ }^{6}$ ), "por que uma dada mudança linguística ocorre em uma determinada época e lugar?". Este é, segundo Labov, a dimensão mais difícil. Nesse sentido, a grande questão é avaliar se um determinado cenário de variação tende a se resolver em função de uma determinada variante, efetivando-se a mudança linguística, ou se as variantes identificadas tendem a se manter no uso linguístico da comunidade, dentro de uma estratificação específica, o que caracterizaria a variação estável.

O estudo aqui empreendido restringiu-se ao problema do encaixamento, abordando questões tanto linguísticas (pessoa do sujeito e tempo verbal) quanto extralinguísticas (gênero, faixa etária e escolaridade) que podem interferir no uso das variantes estudadas.

\subsection{O tempo nos estudos de variação e mudança}

Conforme Cezario e Votre (2011, p.151), "ao analisar o momento atual de uma língua, é difícil dizer se um determinado fenômeno linguístico é um caso de variação estável ou de mudança em curso". Diante disso, os sociolinguistas adotam uma metodologia para dizerem se uma forma está ou não vencendo outra mais antiga: eles analisam o tempo real ou o tempo aparente.

A análise em tempo real pode ser de curta ou longa duração e se dá quando da observação do comportamento de uma variável na mesma comunidade de fala em dois

\footnotetext{
${ }^{4}$ How do members of a speech community evaluate a given change, and what is the effect of this evaluation on the change? The notion of 'evaluation' must be taken here to refer to responses at all levels of awareness, from overt discussion to reactions that are quite inaccessibke to introspection. ${ }^{5}$ How does the system change without damage to its representational function?

${ }^{6}$ Why did a given linguistic change occur at the particular time and place that it did?
} 


\section{Revista do SELL \\ v. $4, n^{\circ} .1$ \\ ISSN: $1983-3873$}

períodos distintos (recorte de vários períodos sincrônicos). Já a análise em tempo aparente se dá por meio de um único recorte sincrônico, enfatizando a análise de uma determinada mudança na perspectiva do fator externo faixa etária.

Labov (1982, p. 31, tradução minha ${ }^{7}$ ) salienta que

estudos no tempo aparente não são suficientes por si só para estabelecer a existência de mudança em progresso. Alguma informação sobre o tempo real, independente de quão limitada, é necessária para eliminar decisivamente a possibilidade de que a graduação por idade observada é estável ao longo do tempo.

Correlacionando variação e mudança, a Teoria da Variação e Mudança (cf. WEINREICH; LABOV; HERZOG [1968], 2006) rompe com a dicotomia saussureana sincronia/diacronia, aproximando-as, visto que, para que os sistemas mudem, é preciso que eles tenham sofrido algum tipo de variação. Cabe ao sociolinguista, explicitar que "a partir de tais e tais características estruturais e de tais e tais condições de funcionamento, o sistema, quase que preditivamente, caminhou na direção $X$ e não na direção Y" (TARALLO, 1994, p.26).

Tendo sido evidenciada a variação num momento sincrônico, atual, por exemplo, volta-se ao passado para o encaixamento histórico das variantes, fechando o ciclo com a chegada novamente ao presente. Dessa forma, pode-se observar (ou não) a manifestação da doutrina do uniformitarismo: alguns mecanismos que operaram para produzir mudanças no passado podem estar operando nas mudanças correntes (LABOV, 1982, p.20). Logo, se olhar o passado pode fornecer indícios para explicar o presente, é possível olhar o presente para projetar o futuro, ou seja, verificar uma mudança em tempo aparente.

As observações em tempo aparente conectadas às observações em tempo real permitem que se verifique a mudança em progresso. A análise da mudança em tempo aparente é apenas um prognóstico, uma projeção que o pesquisador se arrisca a fazer, portanto, constitui-se como uma hipótese. A articulação entre presente e passado permite evidenciar estágios variáveis e mudanças que aconteceram (tempo real) e que estão em curso (tempo aparente).

\footnotetext{
${ }^{7}$ Studies in apparent time are not suficiente in themselves to establish the existence of change in progress. Some real time information, no matter how limited, is needed to eliminate decisively the possibility that the age grading observed is stable over time.
} 


\section{Revista do SELL}

v. $4, n^{\circ} .1$

ISSN: $1983-3873$

Convém, contudo, deixar claro que "nem toda variabilidade e heterogeneidade na estrutura linguística implica mudança, mas toda mudança implica variabilidade e heterogeneidade"(cf. WEINREICH; LABOV; HERZOG, [1968] 2006, p. 125).

Este estudo constitui-se numa abordagem em tempo aparente ao fenômeno da negação no português falado do Rio de Janeiro.

\section{A negação no português brasileiro: breves considerações}

A negação é um fenômeno comum a várias línguas e, de acordo com Roncarati (1997), é tema que oferece múltiplas possibilidades de análise. Presente em todas as línguas, a negação pode se manifestar de formas distintas de uma língua para outra. Sua realização pode ser expressa por meio de recursos morfológicos, sintáticos e lexicais.

Depois dessas considerações sobre a negação como universal linguístico, passemos às considerações sobre a negação no português brasileiro, doravante PB. Existem, em variedades faladas do PB, conforme dados a seguir, três estratégias recorrentes de negação sentencial ${ }^{8}: 1$ ) a negação pré-verbal (não + SV); 2) a negação dupla (não + SV + não) e; 3) a negação pós-verbal (SV + não).

1) a negação pré-verbal (não + SV):

F- A gente não tem tempo para brincar assim, sabe? Que ele trabalha numa oficina (ruído) fazendo biscate- A gente não tem tempo. (est). (PEUL, AMOSTRA CENSO 1980, INFORMANTE 01 , grifos meus)

2) a negação dupla (não + SV + não):

F- ("Acho") que tem uns <vizi...>- tem vizinho que são bons, tem uns que também são vizinho ruim, sabe? (est) Eles gostam de discutir, de ficar, assim, <s...>- falando mal dos outros, sabe? (est) Acho que lá [não]- não tem muito vizinho bom não. (PEUL, AMOSTRA CENSO 1980, INFORMANTE 01, grifos meus)

3) a negação pós-verbal (SV + não):

E- Você chegou a se machucar alguma vez na luta, não?

F- Cheguei a se machucar não. (PEUL, AMOSTRA CENSO 1980, INFORMANTE 01, grifos meus)

A negativa pré-verbal é a variante canônica e por isso nota-se sua predominância em textos escritos, já que essa modalidade da língua é mais resistente às

\footnotetext{
${ }^{8}$ É sabido que há diferentes partículas com funções negativas. Entretanto, neste estudo, serão consideradas as ocorrências com o advérbio não, apontado por Neves (2000) como o principal operador negativo de nossa língua.
} 


\section{Revista do SELL}

v. $4, n^{\circ} .1$

ISSN: $1983-3873$

inovações. Já as variantes inovadoras são bastante comuns na linguagem falada. Furtado da Cunha (2001, p. 2) afirma que "a coexistência desses três mecanismos de negação oracional é interpretada como o resultado da atuação de pressões rivais sobre o sistema linguístico".

A autora (ibidem) explica que os estudos quanto à origem das estratégias de negação do PB consideram duas possibilidades. Na primeira delas, as construções negativas decorrem de uma base crioula ou seriam o resultado de mudanças naturais da língua. De acordo com essa hipótese, a negação pré-verbal vem do português europeu (PE) e a gênese da negação dupla e pós-verbal está na influência da estrutura de línguas africanas. Na segunda possibilidade, cuja hipótese está relacionada à deriva secular das línguas românicas, as formas negativas inovadoras não são construções exclusivas do $\mathrm{PB}$, visto que estudos diacrônicos revelam o uso da dupla negação em textos do PE do século XVI.

Há, no Brasil, na perspectiva funcionalista e variacionista, alguns estudos cujo objeto é a negação. Schwegler (1991) analisa a negação sentencial no português falado no Brasil a partir de dados coletados em São Paulo, Rio de Janeiro e Salvador; Roncarati (1997) investiga o falar de Fortaleza; Camargos (2000) toma em consideração o falar da cidade de Belo Horizonte; Furtado da Cunha $(1996,2000,2001)$ analisa textos orais e escritos pertencentes ao Corpus Discurso \& Gramática - a língua falada e escrita na cidade de Natal; Souza (2004) observa os usos de negação na comunidade afro-brasileira de Helvécia; Santana e Nascimento (2011) analisam a variação linguística na estrutura de negação utilizada na fala da Matinha, comunidade rural da cidade de Feira de Santana (BA); Reimann e Yacovenco (2011) buscam descrever as construções negativas sentenciais do português falado em Vitória/ES.

Aliando a Teoria da Variação à Sintaxe Gerativa, Cavalcante (2007) analisa dados de inquéritos feitos em comunidades de origem africana de três cidades da Bahia Cinzento, Rio de Contas e Sapé.

Muitos destes trabalhos já realizados apresentam em comum menção ao trabalho de Jespersen (1917). Neste trabalho, ao analisar algumas línguas, como o inglês e o francês, o autor propõe um ciclo ${ }^{9}$ para explicar a alternância e mudança das estratégias de negação sentencial.

\footnotetext{
${ }^{9} \mathrm{O}$ ciclo de Jespersen consiste no processo diacrônico através do qual o operador de negação muda de posição dentro da estrutura frasal. Há a passagem de um elemento negativo pré para um
} 


\title{
Revista do SELL \\ v. $4, n^{\circ} .1$ \\ ISSN: $1983-3873$
}

Ao tratar do processo de mudança das estratégias de negação no PB, Magalhães (2012, p. 73) explica que,

\begin{abstract}
em um primeiro momento, a língua expressa a negação por meio de um item pré-verbal e é considerada canônica. Porém, devido a sua posição no início da frase, esse elemento pré-verbal sofre um desgaste fonológico e um enfraquecimento semântico. Esse desgaste desperta a necessidade de expressar a negação acrescentando, concomitantemente ao item préverbal, outros itens com semântica negativa ao final da sentença como garantia da sua compreensão. Esses itens, por sua vez, podem de início não possuir traços de negação e serem opcionais, mas com o uso excessivo e o tempo podem tornar-se uma partícula negativa por excelência e tornar opcional o item pré-verbal.
\end{abstract}

Magalhães (2012) complementa dizendo que esses estágios identificam um processo de mudança linguística no qual é observado um processo cíclico de enfraquecimento, fortalecimento e substituição de elementos.

Furtado da Cunha (2000, p. 167) propõe a representação desse caminho circular da seguinte maneira:

1. reforço opcional da negação através do acréscimo de não pós-verbal;

2. reanálise do não pós-verbal como elemento obrigatório via repetição de uso;

3. redução fonológica do não pré-verbal;

4. eliminação da redundância através da omissão do não pré-verbal.

O trajeto desse fenômeno linguístico é motivado por fatores pragmáticos, cognitivos, sintáticos e fonológicos. Esse ciclo inicia-se na fala quando se dá o enfraquecimento do operador negativo nas construções negativas canônicas. O usuário da língua, quando percebe esse enfraquecimento, tem necessidade de reforçar o sentido da negação para ser compreendido e faz surgir por meio de sua criatividade a construção da dupla negação. O uso repetido dessa construção contribui para sua regularidade que passa a fazer parte da gramática da língua. Porém, como o operador negativo pré-verbal já se encontra em processo de desgaste, chega ao seu limite e é eliminado da construção, fazendo emergir uma nova construção com o operador pós-verbal. (cf. MAGALHÃES, 2012).

pós-verbal, tendo entre esses dois estágios uma fase intermediária em que há coocorrência do elemento pré e pós-verbal na mesma frase. 


\section{Revista do SELL}

v. $4, n^{\circ} .1$

ISSN: $1983-3873$

Ainda sob a ótica do ciclo de Jespersen, é interessante observar que nas línguas estudadas, o inglês e o francês, na transição de um estágio para outro, convivem duas estratégias negativas. No português brasileiro, entretanto, pelos estudos já realizados, nota-se o convívio sincronicamente de três estratégias negativas.

Essa constatação exige cautela na afirmação de que, no português brasileiro, há mudança diacrônica em relação ao fenômeno da negação. Isso é reforçado também pelo fato de os estudos já realizados revelarem que a convivência de formas caracterizase ainda pela predominância das ocorrências da negação canônica, relevando que as variantes inovadoras (dupla negação e negação pós-verbal) não têm tido força suficiente para desbancar a forma inicial.

É neste sentido que justifica a realização de mais estudos sobre esse fenômeno, abarcando dados de diferentes regiões do país, já que poderão revelar similaridades ou diferenças na opção das estratégias de negação. Assim como Furtado da Cunha (2001), acreditamos que o estudo das construções conhecidas como universais linguísticos contribui para o entendimento da natureza do pensamento humano e da interação social na medida em que tais construções parecem refletir universais psicológicos e socioculturais.

\section{Procedimentos metodológicos}

\subsection{Constituição do corpus}

O presente estudo é baseado na Sociolinguística Variacionista Laboviana, modelo teórico cujo objeto de estudo se concentra no uso do vernáculo, isto é, da língua falada em situações naturais de interação social, em que o mínimo de atenção é prestado ao monitoramento da fala.

O corpus de análise para a presente pesquisa é composto por uma subamostra recolhida do PEUL (Programa de Estudos sobre o Uso da Língua). O grupo PEUL reúne pesquisadores que se dedicam ao estudo da variação e mudança linguística na variedade de português falada e escrita no Rio de Janeiro. Adotando uma orientação essencialmente baseada na Sociolinguística Variacionista, os pesquisadores que integram o Peul vêm se dedicando, ao longo de mais de vinte anos, à análise da língua em uso e à sua inter-relação com aspectos sociais, estruturais e funcionais. A sede do PEUL está localizada na UFRJ (Universidade Federal do Rio de Janeiro), de onde faz 


\section{Revista do SELL}

v. $4, n^{\circ} .1$

ISSN: $1983-3873$

parte a maioria dos professores e bolsistas do projeto. $O$ grupo inclui ainda pesquisadores da UFF (Universidade Federal Fluminense) e da Universidade Federal do Espírito Santo. Os corpora constituídos por esses pesquisadores estão disponíveis para download no endereço eletrônico http://www.letras.ufrj.br/peul/amostras\%201.html.

Ao longo de muitos anos, o grupo PEUL tem se preocupado em constituir bancos de dados representativos tanto da modalidade falada quanto da modalidade escrita. Essa preocupação traduziu-se, inicialmente, no projeto Censo da Variação Lingüística com a constituição, no período de 1980 a 1983, do banco de dados que ficou conhecido como Amostra Censo. A amostra Censo serviu de base para a constituição, no período de 1999 a 2000, de duas novas amostras que propiciam a realização de estudos da mudança em tempo real de curta duração, tanto no indivíduo (estudo do tipo painel) como na comunidade (estudo tendência). A fim de atingir objetivos mais específicos, alguns integrantes do grupo constituíram amostras com características mais particulares e que também foram incorporadas ao acervo do Peul.

A Amostra Censo 1980, como ficou conhecido o primeiro banco de dados do grupo, foi coletada no período de 1980 a 1982, sob a coordenação de Anthony Julius Naro, com a participação dos pesquisadores Giselle Machline de Oliveira e Silva, Maria Cecília Mollica, Maria Marta Pereira Scherre, Nelize Pires de Omena e Sebastião Josué Votre. Essa amostra foi coletada, como já dito, observando os pressupostos da Sociolinguística Variacionista Laboviana, com o objetivo de possibilitar o estudo de processos de variação e mudança na variedade carioca. Essa amostra foi estratificada segundo as variáveis idade, escolaridade e sexo. Os falantes foram selecionados aleatoriamente em diferentes bairros da cidade do Rio de Janeiro. A amostra perfaz um total de 48 falantes, correspondendo a 64 horas de gravação, que foram transcritas em um método semiortográfico que busca respeitar características inerentes da fala. Deste total, 8 foram selecionadas para compor a subamostra corpus deste trabalho, conforme quadro a seguir:

Quadro 1: Identificação dos perfis sociais dos informantes da subamostra constituída

\begin{tabular}{|c|c|c|c|c|}
\hline \multirow{2}{*}{ FAIXA ETÁRIA } & \multicolumn{2}{|c|}{$\mathbf{5}$ a 8 anos de escolaridade } & \multicolumn{2}{|c|}{$\mathbf{9}$ a 11 anos de escolaridade } \\
\cline { 2 - 5 } & Masculino & Feminino & Masculino & Feminino \\
\hline $\mathbf{1 5}$ a 25 anos & Inf. 01 & Inf. 05 & Inf. 61 & Inf. 37 \\
\hline 26 a 50 anos & Inf. 09 & Inf. 10 & Inf. 41 & Inf. 29 \\
\hline
\end{tabular}

Fonte: Elaborado pela autora (2013) 


\section{Revista do SELL}

v. $4, n^{\circ} .1$

ISSN: $1983-3873$

\subsection{Tratamento dos dados}

A variável dependente a ser estudada, diferentemente da maioria, que é caracterizada por sua binariedade, é eneária, constituída por três variantes: a negação pré-verbal, a negação dupla e a negação pós-verbal. Já como variáveis independentes, ter-se-ão fatores linguísticos (estruturais) e fatores extralinguísticos (sociais). Após a observação dos possíveis contextos de variação, os aspectos levados em consideração foram: sujeito (1 ${ }^{a}, 2^{\underline{a}}$ e $3^{\underline{a}}$ pessoas) e tempo verbal (Presente, Passado e Futuro); gênero do informante (Masculino e Feminino); faixa etária (Fx. I - 15 a 25 anos, Fx. II - 26 a 50 anos); escolaridade (5 a 8 anos e 9 a 11 anos).

Depois da codificação, todos os dados foram quantificados em tabelas, conforme cada fator linguístico e extralinguístico levado em consideração. Ressalta-se aqui que não foi utilizado nenhum programa estatístico mais elaborado, uma vez que a composição do corpus, se consideradas as orientações da sociolinguística quantitativa laboviana, foi dada com número inferior ao necessário para um estudo mais criterioso. Essa limitação em relação ao corpus se deu em virtude do tempo para elaboração do trabalho e análise dos dados, já que se trata de um trabalho disciplinar realizado durante o curso de Mestrado. Não obstante, destaca-se que isso não anula a credibilidade e importância deste estudo, já que pode ser um indicador de um processo em mudança e que merece ser estudado mais a fundo.

\section{Os recursos de negação no português falado carioca: analisando os dados}

As entrevistas que constituíram o corpus deste estudo foram lidas e nelas foram marcadas todas as ocorrências das estratégias de negação utilizadas pelos falantes. Depois, foram analisados também os fatores linguísticos e sociais relacionados às estratégias marcadas. Primeiro segue tabela 1 com dados quantitativos do uso de cada estratégia negativa. 


\section{Revista do SELL}

v. $4, n^{\circ} .1$

ISSN: $1983-3873$

Tabela 1: Número total de ocorrências das estratégias de negação no corpus

\begin{tabular}{lcc}
\multicolumn{1}{c}{ Variante } & Ocorrências & Porcentagem \\
\hline Negação pré-verbal & 616 & $73,1 \%$ \\
Dupla negação & 214 & $25,4 \%$ \\
Negação pós-verbal & 13 & $1,5 \%$ \\
\hline TOTAL & 843 & $100 \%$ \\
\hline
\end{tabular}

Fonte: Dados do corpus - elaborada pela autora (2013).

Nota-se, a partir dos números apresentados, que, apesar de o corpus ser constituído por amostra de fala, ainda bastante predominante o uso da estratégia canônica. Interessante observar também o baixíssimo número de ocorrências da negação pós-verbal. Isso pode ser um indicador de que o fenômeno ainda é um fenômeno incipiente no que se refere à mudança linguística.

Conforme observado no início deste trabalho, foi considerado em nossos dados somente o operador negativo não e sua variação fônica num. Entretanto, é importante destacar que em duas das ocorrências da negação pós-verbal foi notada a presença de "ninguém", outro termo que pode ser considerado um quantificador negativo, conforme exemplos 1 e 2 .

(1) E - Nossa! Reúne todo mundo assim em festa de natal?

F - Lá ninguém dá festa não. Lá é muito difícil ter festa. Ninguém lá gosta de festa. Festa só na casa dos outros. Hoje em dia está ruim para você, como é que vai convidar os outros? (PEUL, AMOSTRA CENSO 1980, INFORMANTE 09, grifos meus)

(2) $\mathbf{E}-$ Não, mas às vezes família...

F - Não, não. Lá, todo mundo - ninguém é - quando quer visitar, vai visita - mas ninguém é muito de andar um na casa do outro não. Sempre fomos assim. É criação mesmo. (PEUL, AMOSTRA CENSO 1980, INFORMANTE 09, grifos meus)

5.1 Fatores linguísticos: pessoa do sujeito e tempo verbal

O fator linguístico pessoa do sujeito e tempo verbal foi considerado na análise por acreditar que a $1^{\underline{a}}$ pessoa seria mais recorrente nas três estratégias, além de favorecer o uso da dupla negativa, vez que, quando falamos de nós mesmos, tendemos a enfatizar mais os fatos relatados e, como vimos, a dupla negativa serve como ênfase da negação. $O$ fator tempo verbal também foi considerado e hipotetizou-se que o tempo passado seria mais recorrente e também favoreceria o uso da dupla negação em virtude de se tratar de um corpus constituído por entrevistas cujos assuntos giram em torno de curiosidades acerca do entrevistado e as falas dos entrevistados são essencialmente narrativas. 


\section{Revista do SELL}

v. $4, n^{\circ} .1$

ISSN: $1983-3873$

Conforme se vê na tabela 2 (vide também exemplo 3), a primeira hipótese foi confirmada totalmente.

Tabela 2: Ocorrência/frequência das variantes conforme pessoa do sujeito

\begin{tabular}{lcccc}
\hline \multicolumn{1}{c}{ Variantes } & $\mathbf{1}^{\mathbf{a}}$ pessoa & 2 $^{\mathbf{a}}$ pessoa & 3 $^{\mathbf{a}}$ pessoa & Total \\
\hline Negação pré-verbal & $349(56,6 \%)$ & - & $267(43,4 \%)$ & $616(100 \%)$ \\
Dupla negação & $148(69,2 \%)$ & - & $66(30,8 \%)$ & $214(100 \%)$ \\
Negação pós-verbal & $8(61,5 \%)$ & - & $5(38,5 \%)$ & $13(100 \%)$ \\
\hline TOTAL & $505(59,9 \%)$ & - & $338(40,1 \%)$ & $843(100 \%)$ \\
\hline
\end{tabular}

Fonte: Dados do corpus - elaborada pela autora (2013).

(3) E - Mas você não é filha única, não é, Joana?

$\mathbf{F}$ - Não, [eu] - [eu] - eu não sou filha única não, sabe? Eu não sou filha única não. Eu tenho vários irmãos, mas por parte de mãe, sabe? Que meu pai - meu pai - é uma fofoca a minha vida. (PEUL, AMOSTRA CENSO 1980, INFORMANTE 10, grifos meus)

Em relação à pessoa do sujeito, fator de destaque também foi a não ocorrência de nenhuma das variantes na $2^{\underline{a}}$ pessoa, o que corrobora com estudos que demonstram a pouca utilização da $2^{a}$ pessoa verbal na língua portuguesa, principalmente em dados de fala.

Já a segunda hipótese, conforme mostra a tabela 3, foi confirmada apenas parcialmente, visto que o tempo predominante foi o presente. Importante destacar ainda que nenhuma ocorrência no tempo futuro foi encontrada nos dados analisados

Tabela 3: Ocorrência/frequência das variantes conforme tempo verbal

\begin{tabular}{lcccc}
\hline \multicolumn{1}{c}{ Variantes } & Passado & Presente & Futuro & Total \\
\hline Negação pré-verbal & $141(22,9 \%)$ & $475(77,1 \%)$ & - & $616(100 \%)$ \\
Dupla negação & $36(16,8 \%)$ & $178(83,2 \%)$ & - & $214(100 \%)$ \\
Negação pós-verbal & $4(30,8 \%)$ & $9(69,2 \%)$ & - & $13(100 \%)$ \\
\hline TOTAL & $181(21,5 \%)$ & $662(78,5 \%)$ & - & $843(100 \%)$ \\
\hline
\end{tabular}

Fonte: Dados do corpus - elaborada pela autora (2013).

5.2 Fatores sociais: gênero, faixa etária e escolaridade

Em relação ao fator social gênero, os dados encontrados corroboram o postulado de Labov, vez que as mulheres são mais conservadoras, justificando a predominância $(76,2 \%)$ da variante canônica, conforme mostrado na tabela 4. 


\section{Revista do SELL}

v. $4, n^{\circ} .1$

ISSN: $1983-3873$

Tabela 4: Ocorrência/frequência das variantes conforme gênero

\begin{tabular}{lcc}
\multicolumn{1}{c}{ Variantes } & Masculino & Feminino \\
\hline Negação pré-verbal & $264(69,3 \%)$ & $352(76,2 \%)$ \\
Dupla negação & $109(28,6 \%)$ & $105(22,7 \%)$ \\
Negação pós-verbal & $8(2,1 \%)$ & $5(1,1 \%)$ \\
\hline TOTAL & $381(100 \%)$ & $462(100 \%)$ \\
\hline
\end{tabular}

Fonte: Dados do corpus - elaborada pela autora (2013).

Já em relação ao fator faixa etária, as postulações labovianas demonstram que as variantes inovadoras são mais comuns em faixa etária jovem. Entretanto, essas postulações não se confirmam totalmente nos dados deste trabalho, visto que do total de 13 ocorrências da negação pós-verbal, variante inovadora, apenas 3 ocorrem na faixa etária 15 a 25 anos e 10 ocorrem na fala de usuários da língua com idade entre 26 e 50 anos. Já a outra variante inovadora, a dupla negação, é mais recorrente entre os mais jovens (116).

Tabela 5: Ocorrência/frequência das variantes conforme faixa etária

\begin{tabular}{lcc}
\hline \multicolumn{1}{c}{ Variantes } & $\mathbf{1 5}$ a 25 anos & 26 a 50 anos \\
\hline Negação pré-verbal & $235(66,4 \%)$ & $381(77,9 \%)$ \\
Dupla negação & $116(32,8 \%)$ & $98(20 \%)$ \\
Negação pós-verbal & $3(0,8 \%)$ & $10(2,1 \%)$ \\
\hline TOTAL & $354(100 \%)$ & $489(100 \%)$ \\
\hline
\end{tabular}

Fonte: Dados do corpus - elaborada pela autora (2013).

Por fim, quanto à escolaridade, observou-se, conforme os dados analisados, que as variantes inovadoras, dupla negação e negação pós-verbal, são mais recorrentes entre os usuários com menor escolaridade, o que também é postulado pela teoria laboviana. Porém, um fato interessante observado em relação a este fator foi a ocorrência em maior número da variedade canônica entre usuários com menos tempo de escolaridade. Conforme se vê na tabela 6 , do total de 616 ocorrências da negação préverbal, 324 foram encontradas em falas de usuários com tempo de escolaridade de 5 a 8 anos e 292 em falas de usuários com tempo de escolaridade de 9 a 11 anos, conforme mostrado na tabela 6 . 
Tabela 6: Ocorrência/frequência das variantes conforme escolaridade

\begin{tabular}{lcc}
\multicolumn{1}{c}{ Variantes } & $\mathbf{5}$ a $\mathbf{8}$ anos & 9 a 11 anos \\
\hline Negação pré-verbal & $324(69,6 \%)$ & $292(77,2 \%)$ \\
Dupla negação & $131(28,2 \%)$ & $83(22 \%)$ \\
Negação pós-verbal & $10(2,2 \%)$ & $3(0,8 \%)$ \\
\hline TOTAL & $465(100 \%)$ & $378(100 \%)$ \\
\hline
\end{tabular}

Fonte: Dados do corpus - elaborada pela autora (2013).

Para uma visualização panorâmica, os dados foram tabulados em um único quadro, conforme se vê a seguir.

Quadro 2: Tabulação quantitativa de todas as variáveis sociais

\begin{tabular}{|c|c|c|c|c|c|}
\hline \multirow{3}{*}{ VARIANTES } & \multirow{3}{*}{ FAIXA ETÁRIA } & \multicolumn{4}{|c|}{ ESCOLARIDADE/GÊNERO } \\
\hline & & \multicolumn{2}{|c|}{$\begin{array}{l}5 \text { a } 8 \text { anos de } \\
\text { escolaridade }\end{array}$} & \multicolumn{2}{|c|}{$\begin{array}{l}9 \text { a } 11 \text { anos de } \\
\text { escolaridade }\end{array}$} \\
\hline & & Masculino & Feminino & Masculino & Feminino \\
\hline Pré-verbal & \multirow{3}{*}{15 a 25 anos } & $\begin{array}{c}52 \\
(67,5 \%)\end{array}$ & $101(68,7 \%)$ & $\begin{array}{c}38 \\
(53,5 \%)\end{array}$ & $44(74,6 \%)$ \\
\hline Dupla negação & & $\begin{array}{c}25 \\
(32,5 \%)\end{array}$ & $46(31,3 \%)$ & $\begin{array}{c}32 \\
(45,1 \%)\end{array}$ & $13(22 \%)$ \\
\hline Pós-verbal & & $0(0 \%)$ & $0(0 \%)$ & $1(1,4 \%)$ & $2(3,4 \%)$ \\
\hline Pré-verbal & \multirow{3}{*}{26 a 50 anos } & $\begin{array}{c}85 \\
(67,5 \%)\end{array}$ & $86(74,8 \%)$ & $\begin{array}{c}89 \\
(83,2 \%) \\
\end{array}$ & $\begin{array}{c}121 \\
(85,8 \%) \\
\end{array}$ \\
\hline Dupla negação & & $34(27 \%)$ & $26(22,6 \%)$ & $\begin{array}{c}18 \\
(16,8 \%)\end{array}$ & $20(14,2 \%)$ \\
\hline Pós-verbal & & $7(5,5 \%)$ & $3(2,6 \%)$ & $0(0 \%)$ & $0(0 \%)$ \\
\hline
\end{tabular}

Fonte: Dados do corpus - elaborado pela autora (2013).

\section{Considerações finais}

O presente estudo teve por objetivo analisar as estratégias de negação sentencial do português falado do Rio de Janeiro. As análises foram feitas a partir de dados de 8 amostras do PEUL e permitiram constatar que a negação pré-verbal, a variante canônica, ainda é a estratégia mais utilizada entre os falantes cariocas, atingindo um percentual de $73,1 \%$ dos 843 dados analisados.

As análises também permitiram constatar que o uso de uma ou outra estratégia de negação pode ser favorecido por algumas variáveis linguísticas e sociais. Os resultados comprovam que todas as variantes são favorecidas pela $1^{\text {a }}$ pessoa do presente, destacando-se, com maior porcentagem, a dupla negação, com $69,2 \%$ das ocorrências em $1^{1}$ pessoa e $83,2 \%$ no tempo presente. 


\section{Revista do SELL}

v. $4, n^{\circ} .1$

ISSN: $1983-3873$

As variáveis sociais gênero, faixa etária e escolaridade também exercem influência na opção pelas estratégias negativas. Corroborando com a teoria laboviana, os resultados encontrados demonstram que o gênero masculino, a faixa etária mais jovem (15 a 25 anos) e o menor grau de escolaridade (5 a 8 anos) favorecem o uso da dupla negação, a variante inovadora mais recorrente. Entretanto, não corroborando totalmente a teoria laboviana, a variante inovadora negação pós-verbal, pouco recorrente nos dados (somente 13 ocorrências), é favorecida pelo gênero masculino, faixa etária mais velha (26 a 50 anos) e menor grau de escolaridade (5 a 8 anos). O fato de o maior número de ocorrências se dar numa faixa etária mais velha vai contra o que afirma Tarallo (1994, p. 65-66), pois, para ele, "para se atestar a mudança em progresso [...] é necessário que as variantes sejam correlacionadas aos diversos grupos etários: maior incidência nas faixas mais jovens e menor freqüência nas mais velhas."

Apesar disso, os dados encontrados e as análises empreendidas da variável estudada demonstram que a negação sentencial do português falado no Rio de Janeiro constitui num fenômeno de mudança em andamento. Entretanto, para confirmação desse processo, necessário se faz o desenvolvimento de outros estudos que contemplem corpus mais volumosos e que utilizem de maior rigor metodológico, inclusive com a utilização de softwares estatísticos que podem auxiliar nas análises quantitativas (VARBRUL, por exemplo). Além disso, outros fatores internos e externos podem ser considerados nestes estudos.

Não obstante a limitação deste estudo, os resultados encontrados foram similares a estudos antes realizados com dados de outras regiões brasileiras. Espera-se, dessa forma, que este possa servir de contribuição para um melhor conhecimento da língua falada no Rio de Janeiro, caracterizando, por sua vez, a língua falada no Brasil, especialmente no que diz respeito às estratégias de negação sentencial.

\section{Referências}

CEZARIO, Maria Maura; VOTRE, Sebastião. Sociolinguística. In: MARTELOTTA Mário Eduardo (Org.). Manual de linguística. São Paulo: Contexto, 2008.

FURTADO DA CUNHA, Maria Angélica. Variação e mudança no domínio funcional da negação. GRAGOATÁ, Niterói, 2000, n. 9, p. 155-170, 2. sem.

FURTADO DA CUNHA, Maria Angélica. O modelo das motivações competidoras no domínio funcional da negação. D.E.L.T.A., vol. 17, n. 1. São Paulo, 2001. p. 1-30. 


\section{Revista do SELL}

v. $4, n^{\circ} .1$

ISSN: $1983-3873$

GONÇALVES, Sebastião Carlos Leite; LIMA-HERNANDES, Maria Célia; CASSEBGALVÃO, Vânia Cristina (orgs.). Introdução à gramaticalização: princípios teóricos e aplicação. São Paulo: Parábola, 2007.

JESPERSEN, Jens Otto. Negation in English and other languages. Copenhagen: Videnskabenes Selskab, 1917.

LABOV, William. Padrões sociolinguísticos [1972]. Trad. Marcos Bagno, Maria Marta Pereira Scherre, Caroline Rodrigues Cardoso. São Paulo: Parábola, 2008.

LABOV, William. Building on Empirical Foundations. In: LEHMANN, W. P. \& MALKIEL, Yakov. (eds.) Perspectives on Historical Linguistics. Amsterdam/Philadelphia: John Benjamins, 1982, p. 17-92.

MAGALHÃES, Felício Zoraide. Nunca vi não: estratégias discursivas de negação na região oeste da Bahia. 118 fls. Dissertação de mestrado. Universidade do Estado da Bahia. Departamento de Ciências Humanas. Programa de Pós-graduação em Estudo de Linguagens. Salvador, BA, 2010.

NEVES, Maria Helena de Moura. Gramática de usos do português. São Paulo: UNESP, 2000 .

RONCARATI, Cláudia. Ciclo aquisitivo da negação. In: RONCARATI, Cláudia \& MOLLICA, M.C (orgs.). Variação e aquisição. Rio de Janeiro: Tempo Brasileiro: 1997, p. 3-16.

TARALLO, Fernando. A pesquisa sócio-linguística. 4. ed. São Paulo: Ática, 1994.

WEINREICH, Uriel; LABOV, William; HERZOG, Marvim I. Fundamentos Empíricos para uma Teoria da Mudança Linguística [1968]. Trad. Marcos Bagno; revisão técnica Carlos Alberto Faraco. São Paulo: Parábola, 2006.

www.letras.ufrj.br/peul/amostras 